\title{
Interpretation of legal obligations of a person and a citizen in the field of environmental protection
}

\author{
Emzari Yunusov ${ }^{1, *}$ \\ ${ }^{1}$ Research Institute of the Federal Penitentiary Service of Russia, Narvskaya str., 15 a, building 1, \\ Moscow, 125130, Russian Federation
}

\begin{abstract}
The article examines legal duties of a person and a citizen, which is a toolkit in the process of learning the proper, socially significant behavior of legally liable subjects of legal relations. The author proposes a classification of legal duties according to various criteria. The classification of legal duties is an integral part of legal regulation and it is of particular importance in the life of society and state.
\end{abstract}

\section{Introduction}

The scientific article is conditioned by theoretical and practical significance. Among the large number of various existing issues in the field of law, which have a significant connection with the construction of the rule of law, the issue of legal duties occupies a special place. Legal duties are one of the most effective means of developing legal relations, creating legal and moral consciousness of citizens, as well as fully strengthening the rule of law and legality. It should be noted that legal duties greatly facilitate the activities and effective functioning of all existing legal systems in the state, which determines their undoubted importance.

Speaking about responsibilities, one cannot but dwell on their classification, whichcan have many grounds due to the multifaceted nature of this phenomenon.

Duty, like law, arises as a necessary condition for objectification, giving form to existing social relations in need of legal protection. The variety of normative structures of public legal duty is conditioned by the variety of existing social relations that require legal normative mediation. Classification of legal duties is possible and necessary, taking into account the needs of normative consolidation of legal duties of a person as a subject of public legal relations. In this regard, classification of legal duties is of great practical importance for the purpose of improving the regulatory design of legal relations-models, on the one hand, and increasing the efficiency of the process of exercising law as a stage of legal impact on public relations, on the other hand.

\section{Methods}

\footnotetext{
*Corresponding author: a.copytowa@yandex.ru
} 
The presented topic is theoretically poorly studied, but certain issues concerning the duties of a person and a citizen have been and remain the object of study of legal scholars: S.S. Alekseev, P.V. Anisimov, Yu.G. Arzamasov, B.C. Afanasyev, S.V. Bakhnin, S.N. Bocharova, S.N. Bratusya, V.N. Butylin, N.V. Vitruk, L.D. Voevodin, I.V. Goncharov, M.Yu. Gorlach, N.L. Garnet, R.E. Gukasyan, A.A. Guseinov, S.F. Kechekian, B.A. Kistyakovsky, M.M. Kovalevsky, N.M. Kolosov, A.V. Kornev, O.E. Kutafin, V.V. Lazarev, E.A. Lukasheva, F. Lyusher, A.V. Malko, G.V. Maltsev, M.N. Marchenko, V.A. Maslennikov, N.I. Matuzov, R.S. Mulukaev, B.C. Nersesyants, N.V. Novoselova, F.M. Rudinsky, A.E. Suntsov, V.A. Kolstik, A.N. Tsukanov, V.E. Chirkin, B.S. Ebzeev and others.

The issues of legal duties were widely touched upon in the works of domestic and foreign philosophers and legal scholars of past centuries: G.V.F. Hegel, M.T. Cicero, T. Hobbes, I. Kant, J. Locke, Sh.L. Montesquieu, J.J. Russo, N.M. Korkunov, P.I. Novgorodtsev, L.I. Petrazhitsky, E.N. Trubetskov, L.L. Gervagen, B.N. Chicherin, G.F. Shershenevich, N.N. Alekseev, I.A. Ilyin, N.A. Berdyaev and others.

These authors investigated various general theoretical aspects of ensuring the rights and implementation of the duties of a person and a citizen. Nevertheless, there are currently no comprehensive studies of the issue of legal duties of a person and a citizen.

In the process of writing a scientific article, dialectical method of scientific knowledge was used. From the standpoint of this method phenomena and objects were considered comprehensively, in movement, development, interconnection and interaction with other phenomena and the environment. General scientific (analysis, synthesis, deduction, induction, analogy, systemic-structural, functional, etc.) and specific scientific (formal legal, comparative jurisprudence, philological, etc.) methods were based on the dialectical method. Particular attention is paid within the framework of the methodology to the activity, instrumental and functional approaches to the issue of classification of legal duties of a person and a citizen.

\section{Results}

The study shows that the variety of rights, freedoms and duties in the legal system allows us to raise the question of grouping them into related classes (groups) on the basis of one or another distinctive feature, i.e. to classify rights and duties in order to study their legal nature and significance.

The classification of duties and rights as a research technique is subjective, i.e. every scientist has the right to have his/her own view of the issue. Therefore, it would be a mistake to insist on the universal nature of one or another classification of these categories, because even a very perfect classification of rights and duties does not exclude, but presupposes other typesof classifications. Thus, any proposed classification of both rights and duties does not claim to be exclusive and is not exhaustive: firstly, certain types of duties can be further subdivided into subtypes of duties; secondly, the types of duties do not exist in their pure form, but are intertwined and interpenetrated in various ways.

There are classifications that have earned a generally recognized value, but there are also those that are of an individual or private nature. The presence or absence of certain classifications of rights and duties in the legal studies of the authors depends on many criteria. This is the individual approach of the author in the research being undertaken, the level of elaboration of the legal framework of legislation and the presence of various in content, clearly expressed and defined duties in a relatively large number. This is the typology of social relations, and the mass level of legal awareness and legal culture of society at a certain stage of its development, and the specifics of the state structure, i.e. form of government, political regime and other criteria. 


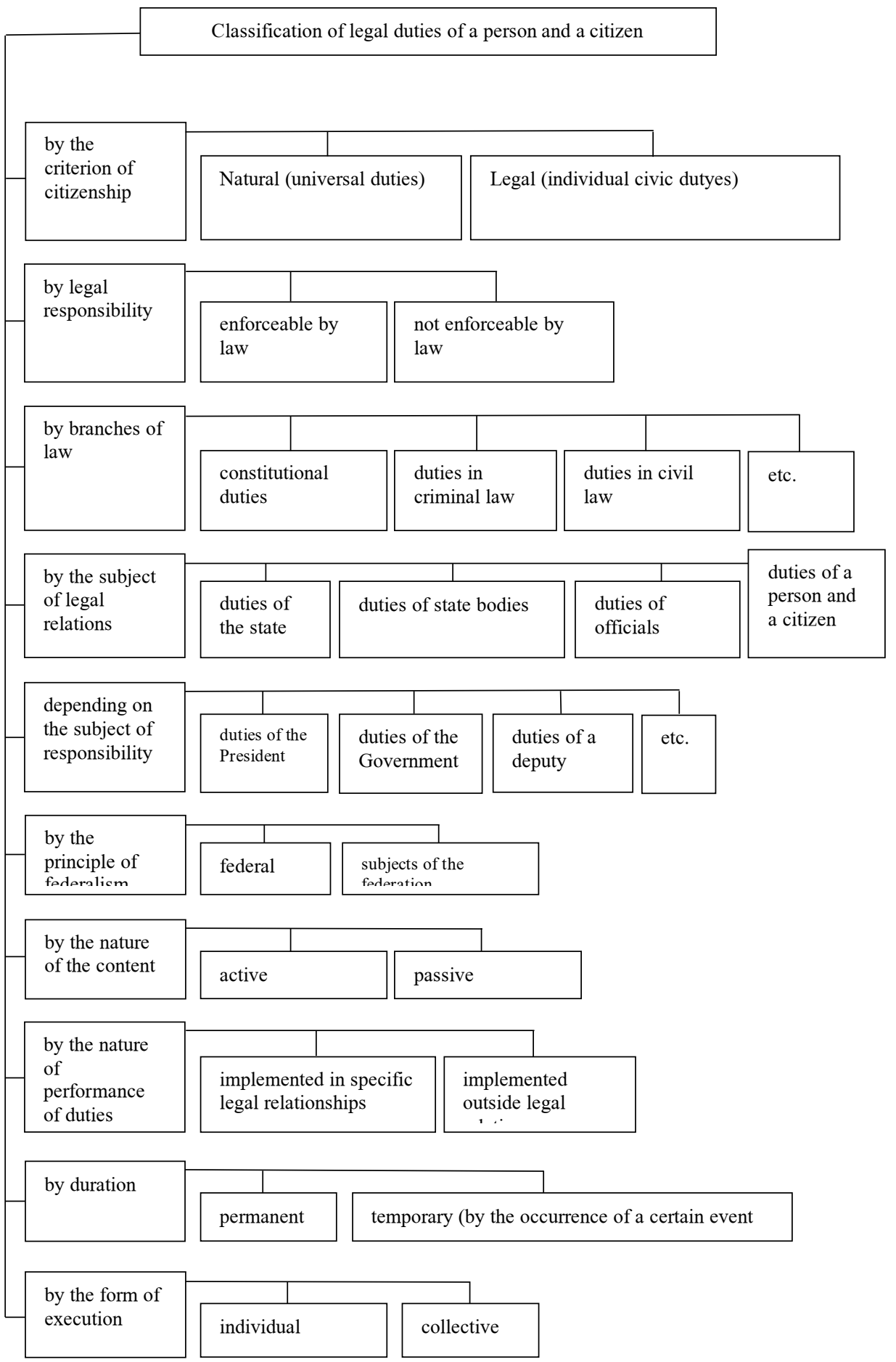

Fig. 1. Classification of legal duties of a person and a citizen. 
Practically all authors, who described the legal nature of duties in one way or another, were involved in the classification of duties, definition of their types, therefore in the science of the theory of law there are many examples of systematization of duties by type. Some authors group duties in unity with rights, others separate from them. Any classification is conditional, because gives an approximate, not absolute, distribution of duties. This does not implore its importance in solving the challenges facing science, society and the state.

The classification of duties as a legal phenomenon is possible on various grounds: origin, subject of legal regulation, constitutional and legal (basic) duties, branches of law, subjects of legal relations, subject of social and legal duty, form of fulfillment of duties, nature of implementation of duties in the field of personal security and private life ... This classification makes possible clear implementation of duties.

\section{Discussion}

In order to reveal the topic, it is important to understand that the social value of a person is determined not only by the fact that he/she is given broad rights. It is also measured by how conscientiously he/she fulfills his/her duties. The set of freedoms, rights and duties in the system of law makes it possible to raise the question of grouping them into related classes (groups) on the basis of one or another distinctive feature, to classify rights and duties in order to study their legal nature and significance.

Classification of basic rights and duties of citizens was proposed for the first time in state law by M.P. Kareva on the example of the USSR Constitution of 1936. She subdivided them into basic rights of citizens in the field of economic and socio-cultural life, constitutional foundations of equality of citizens, basic rights of citizens in state and sociopolitical life, personal freedoms of citizens.

This classification had many shortcomings: only rights were grouped in it, and not taken as a unity of rights and duties; the place of equality in the classification remains unclear; it is interpreted as a special group of rights, and not as their principle. These disadvantages persist to a greater or lesser extent in the classification options put forward after that by many other authors.

The importance and necessity of classifying rights and duties was pointed out by such authors as S.F. Kechekian, A.G. Mozokhina, A.P. Lepeshkin and others.

There are classifications that not only deserve general recognition, but also have an individual or private character. The presence or absence of certain classifications of rights and duties in the legal studies of the authors depends on many criteria. This is an individual approach of the author, and the level of elaboration of the legal framework of legislation and the presence of various in content, clearly expressed and definite legal duties in a relatively large number, and the typology of social relations, and the mass level of legal awareness and legal culture of society at a certain stage of its development, and the specifics of state structure, that is, the form of government, political regime, and other criteria.

The classification of duties as a legal phenomenon is possible according to various criteria. Based on the criterion of citizenship, it is advisable to single out universal duties that belong to each person, and, accordingly, individual civic duties belonging to a citizen of a particular state.

So, according to V.D. Perevalov, duties are subdivided into natural, which are carried by the person and society, and legal, which are carried by citizens, the state and its bodies. In this case, natural duties are understood as duties that are not legally formalized, and the same duties that have been enshrined in the legislation of certain countries.

It is necessary to distinguish between the duties of a person and the duties of a citizen, 
because not all people have the status of a citizen of any state (for example, stateless). Accordingly, from this stable legal relationship between a person and the state, additional duties arise that are characteristic only for citizens of a particular state (for example, the duty to protect the Fatherland, enshrined in Article 59 of the Constitution of Russian Federation). Similar duties to protect the country are enshrined in Art. 31 of the Political Constitution of the United Mexican States, at Art. 52 of the Constitution of the PRC, in part 3 of section. 2 tbsp. IV of the French Constitution. We propose to call the duties belonging to each person universal, and accordingly oppose the duties of a citizen.

Responsibilities should be highlighted. There are duties that, in case of non-fulfillment, are provided with the sanction of a legal norm, and those dutirs that are not provided for with a sanction in case of violation.

Duties of the second type as a means of regulating social relations are objective in nature, they exist independently of our consciousness, because they can act or borrow features of such categories as rights, principles, goals, objectives, obligations. These duties are typical for such branches of law as constitutional and administrative, etc. On the other hand, the existence of such a group of duties is explained by gaps in the current legislation and its ineffectiveness, low level of legal awareness and legal culture.

The duties of the first type can be most clearly represented in criminal, administrative, civil law, etc.

It is necessary to distinguish between duties that are formal or substantive in nature, one can also talk about duties that are partly formal, partly emotional or evaluative. For example, this concerns the duties of public authorities, officials who perform duties not only because of their formal necessity, but also out of internal approval and desire to fulfill the task, to achieve a qualitatively positive result in their work.

One can classify duties by their nature. According to V.I. Chervonyuk, a legal duty can be active in nature (for example, fulfillment of an employment obligation) and passive in nature. If the active nature consists in the need to take positive actions, then the passive nature of legal duty consists in refraining from committing certain socially harmful or socially dangerous actions (for example, prohibited by the norms of the Special Part of the Criminal Code of Russian Federation). A legal duty may consist in undergoing unfavorable legal consequences (responsibility for a committed offense).

L. Sh. Berekashvili and V.P. Ignatov distinguishes between following legal duties: to perform certain actions, to refrain from committing prohibited actions, to demand the commission or noncommission of actions from other persons, to be held liable for failure to perform the prescribed actions.

It is necessary to distinguish by the nature of implementation of duties that are implemented in specific legal relations (for example, the duty to pay legally established taxes and fees (Article 57 of the Constitution of Russian Federation)) and duties realized outside legal relations, and only their failure to fulfill them can give rise to specific legal relations (the duty to comply with the Constitution and laws (article 15 of the Constitution of Russian Federation)). This classification helps to establish the characteristics of implementation of individual duties.

According to the level of requirements for the personality, one can distinguish: permanent duties that must be performed constantly; duties that must be performed upon the occurrence of a certain event specified in the norm; duties that are performed at the request of a person vested with the appropriate rights.

According to the form of performance, duties can be divided into individual (everyone is obliged to take care of preservation of historical and cultural heritage, to protect the monuments of history and culture (part 3 of article 44 of the Constitution of Russian Federation) and collective. As a rule, duties are individual in nature.

One of the most significant grounds for classification of duties is a sectoral feature, that 
is, the presence of duties arising from any specific branch of law (duties enshrined in constitutional law, criminal, civil, labor, environmental and other branches of substantive and procedural law).

If we classify the main duties by the subject of legal relations, then we should distinguish between the duties of the state, state bodies and officials, on the one hand, and the duties of a person and citizen, on the other hand. For example, the state is obliged to recognize, observe and protect the rights and freedoms of man and citizen (Art. 2 of the Constitution of Russian Federation); The Constitutional Court is obliged to strive for selfrestraint both in order to eliminate interference in the competence of other branches of government, and to avoid solving political problems in the country; the duty of the Chairman of the Government is to submit to the President of Russian Federation a proposal on the structure of federal executive bodies no later than a week after the appointment (part 1 of article 112 of the Constitution of Russian Federation).

It should be noted that there are duties of the state, state bodies and officials aimed at performing certain functions. For example, in order to implement the calculation and analytical function, the Government of Russian Federation is obliged to submit to the State Duma a report on the execution of the federal budget, etc.

According to the forms of definition of constitutional duties, the duties enshrined in the Constitution of Russian Federation and constitutional laws should be divided; duties enshrined in other laws and regulations; duties enshrined in contracts.

Depending on the subject of responsibility, one can distinguish: duties of the President of Russian Federation, duties of the Government of Russian Federation, duties of deputies, duties of judges, etc.

Based on the federal structure of Russian Federation, it is necessary to distinguish between the duties of the state and the duties of the subject of Federation. S.N. Chernov proposes following duties of the constituent entity of Russian Federation: to directly apply the Constitution of Russian Federation, which has supreme legal force on the territory of the constituent entity of Russian Federation (part 1 of article 15 of the Constitution of Russian Federation); to comply with the Constitution of Russian Federation and laws (part 2 of article 15 of the Constitution of Russian Federation); to recognize, observe and protect human and civil rights and freedoms (Article 2 of the Constitution of Russian Federation); to possess state power and exercise state power (part 2 of article 11 of the Constitution of Russian Federation); to officially publish laws (part 3 of article 15 of the Constitution of Russian Federation); not to apply normative legal acts affecting the rights, freedoms and obligations of a person and a citizen, if they are not officially published for general information (part 3 of article 15 of the Constitution of Russian Federation) and other legal duties of a subject of Russian Federation.

Practically all authors, who described the legal nature of duties in one way or another, were involved in the classification of legal duties, definition of their types, therefore in the science of the theory of law there are many examples of systematization of duties by type. Some authors group duties in unity with rights, others separate from them. Any classification is conditional, since it gives an approximate, not absolute, distribution of legal duties. This does not diminish its importance in solving the challenges facing science, society and the state.

Classification of legal duties is subjective. Each author has the right to have his/her own view of the problem, so it would be a mistake to insist on the universal nature of one or another classification of these categories, since even a very perfect classification of rights and duties does not exclude, but presupposes other types.

\section{Conclusion}


Summing up, and based on the foregoing, it can be noted that any proposed classification of legal duties does not claim to be exclusive and is not exhaustive: firstly, certain types of duties can be further subdivided into subtypes of duties; secondly, the types of duties do not exist in their pure form, but are intertwined and interpenetrated in various ways.

The classification system can be further developed within the above mentioned groups of legal duties and should be based on objective criteria underlying the classified phenomenon.

\section{Acknowledgments}

The author expresses deep gratitude to the leadership of the Research Institute of the Federal Penitentiary Service of Russia for the help and support provided during this study.

\section{References}

1. E.A. Yunusov, S.M. Vorobiev, A.G. Akhverdyan, A.G. Grunin, R.D. Khritin, Dilemas contemporáneos: Educación, Política y Valores 7(S10), 83 (2019)

2. M.A. Yunusov, E.A. Yunusov, Black holes in Russian legislation 3, 50-52 (2015)

3. A.N. Zherebtsov, General theory of public duty (Publishing house "Legal CenterPress", SPb, 2013)

4. E.A. Yunusov, Altai legal bulletin 3(15), 52-56 (2016)

5. N.Ya. Kupressa, Soviet state law (M., 1950)

6. A.I. Denisov, M.G. Kirichenko, Soviet state law (M., 1957)

7. S.F. Kechekian, Legal relations in a socialist society (M., 1958)

8. A.G. Mozokhina, Individual freedom and fundamental rights of citizens in the socialist countries of Europe (M., 1965)

9. A.I. Lepeshkin, The course of Soviet state law (M., 1961)

10. V.D. Perevalov, Theory of state and law (M., 1995)

11. N.I. Matuzov, Actual problems of the theory of law: Monograph (Saratov, 2003)

12. V.I. Goyman-Chervonyuk, Essay on the theory of state and law (M., 1996)

13. L.Sh. Berekashvili, V.P. Ignatov, Ensuring human rights and legality in the activities of law enforcement agencies (M., 2003)

14. E.P. Radchenko, M.G. Olenev, Bulletin of the public research laboratory "Interaction of the penal system with civil society institutions: historical-legal and theoreticalmethodological aspects" 14, 131-136 (2019)

15. S.N. Chernov, Constitutional and legal status of the Republic of Karelia: Monograph (SPb, 2003)

16. A.A. Yunusov, E.A. Yunusov, N.V. Zhezlov, Modern law 4, 24-27 (2019)

17. V.F. Lapshin, S.A. Korneev, E3S Web of Conferences 135, 04063 (2019) DOI: 10.1051 / e3sconf / 201913504063 